\title{
Simvastatin Inhibits Candida albicans Biofilm In Vitro
}

\author{
GEOFFREY LIU, VINCENT F. VELLUCCI, STEPHANIE KYC, AND MARGARET K. HOSTETTER \\ Department of Pediatrics, Yale School of Medicine, New Haven, Connecticut 06520
}

\begin{abstract}
By inhibiting the conversion of 3-hydroxy-3methylglutaryl CoA (HMG-CoA) to mevalonate, statins impair cholesterol metabolism in humans. We reasoned that statins might similarly interfere with the biosynthesis of ergosterol, the major sterol of the yeast cell membrane. As assessed by spectrophotometric and microscopic analysis, significant inhibition of biofilm production was noted after 16-h incubation with $1,2.5$, and $5 \mu \mathrm{M}$ simvastatin, concentrations that did not affect growth, adhesion, or hyphal formation by $C$. albicans in vitro. Higher concentrations (10, 20, and 25 $\mu \mathrm{M}$ simvastatin) inhibited biofilm by $>90 \%$ but also impaired growth. Addition of exogenous ergosterol $(90 \mu \mathrm{M})$ overcame the effects of 1 and $2.5 \mu \mathrm{M}$ simvastatin, suggesting that at least one mechanism of inhibition is interference with ergosterol biosynthesis. Clinical isolates from blood, skin, and mucosal surfaces produced biofilms; biofilms from bloodstream isolates were similarly inhibited by simvastatin. In the absence of fungicidal activity, simvastatin's interruption of a critical step in an essential metabolic pathway, highly conserved from yeast to man, has unexpected effects on biofilm production by a eukaryotic pathogen. (Pediatr Res 66: 600-604, 2009)
\end{abstract}

$\mathrm{C}$ andidemia is the fourth most common cause of bloodstream infection in hospitalized patients, with Candida albicans predominating (1). Hosts at greatest risk include burn patients, postpump cardiac surgery patients, neutropenic oncology patients, premature newborns, and patients recovering from abdominal surgery. In these groups, the incidence of candidemia ranges from 0.7 to 1.6 cases per 1000 discharges (2).

Age also exerts a profound effect, with the incidence in neonates (1.6 per 1000) about 8-fold greater than in adults (3). Premature newborns have significant higher risk, with an infection rate rising from 10 per 1000 in infants weighing 1001 to $1500 \mathrm{~g}$ to 75 per 1000 in infants $\leq 800 \mathrm{~g}$ (4). In all of these high-risk groups, mortality exceeds $25 \%$ in many studies (5-9). A common risk factor is the presence of central venous catheters $(4,10)$ that serve as a site for the development of biofilm, composed of layers of yeast cells, hyphae, and a profuse exopolysaccharide matrix that renders the biofilm impenetrable to antibiotics and host defenses (11-13).

Received June 22, 2009; accepted August 19, 2009

Correspondence: Margaret K. Hostetter, M.D., Yale School of Medicine, 333 Cedar Street, LMP 4085, P.O. Box 208064, New Haven, CT 06520; e-mail: Margaret.Hostetter@yale.edu

Supported in part by the Jean McLean Wallace Professorship at Yale School of Medicine (M.K.H.).

The first two authors contributed equally to this work.
Clinical studies (14-17) and national guidelines $(18,19)$ have emphasized that treatment of candidemia in those patients with a central venous catheter in place requires removal or replacement of the catheter, in addition to antifungal therapy, although catheter removal may disrupt the delivery of lifesaving chemotherapy, parenteral nutrition, antibiotics, or blood products. Although prophylaxis with fluconazole has proven effective in the prevention of Candida colonization in premature newborns as well as pediatric and adult oncology patients, the effect on mortality ascribable to candidemia has been variable (20-22). Thus, additional strategies for the prevention or impairment of biofilm production by $C$. albicans could be helpful.

Recently, our laboratory characterized two mitochondrial mutants in which the generation of acetyl CoA is impaired $(23,24)$. Deletion of both copies of the gene encoding either complex I of the electron transport chain (NDH51) or pyruvate dehydrogenase complex protein $\mathrm{X}(P D X 1)$ blocks the generation of acetyl CoA. Although we originally reported that these mutants displayed a wild-type phenotype with regard to growth, replication or hyphal formation in rich medium $(23,24)$, we subsequently found that biofilm formation, as indicated by safranin staining of exopolysaccharide matrix, was significantly impaired in both mutants (Fig. 1) (25-27).

We therefore hypothesized that other inhibitors of acetyl CoA metabolism, such as the statins, might impair biofilm formation in C. albicans even without concomitant fungicidal effects. In higher eukaryotes, statins reversibly and competitively inhibit hepatic cholesterol synthesis from acetyl CoA by inhibiting 3-hydroxy-3-methylglutaryl CoA (HMG-CoA) reductase, which converts HMG-CoA to mevalonate $(28,29)$. In more primitive eukaryotes such as Candida albicans, comparable steps in this essential pathway are highly conserved, but the final product is ergosterol, the major sterol of the yeast cell membrane (30). Therefore, we designed experiments to determine whether targeting an essential metabolic pathway in $C$. albicans could exert an inhibitory effect on production of biofilm by $C$. albicans in vitro in the absence of fungicidal activity.

\section{METHODS}

Chemicals. Simvastatin (Sigma Chemical Co.-Aldrich), provided in the form of a lactone prodrug, was activated by solubilization in $15 \%$ ( $\mathrm{vol} / \mathrm{vol})$

Abbreviations: YPD, yeast peptone dextrose 


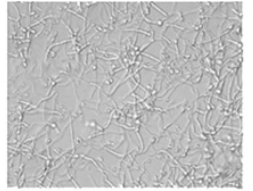

WT
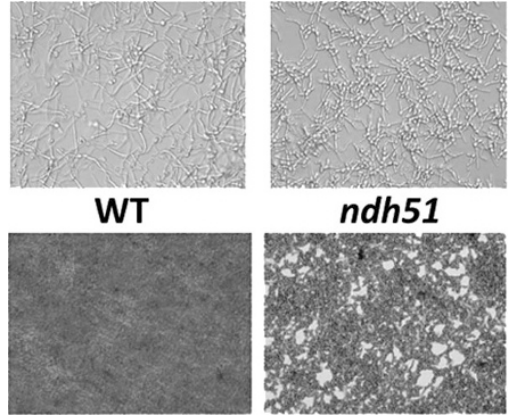

ndh51

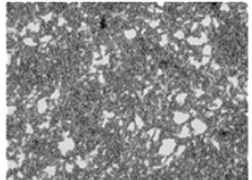

$p d \times 1-29$

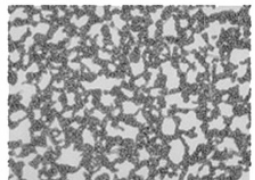

Figure 1. Photos in top row illustrate hyphal formation in rich radium for wild-type (WT) strain and isogenic mutants deleted in the $51 \mathrm{kDa}$ subunit of nicotinamide adenine dinucleotide dehydrogenase complex I (ndh51) or in pyruvate dehydrogenase complex protein X ( $p d x 1-29)$; photos in bottom row show safranin staining of corresponding mature biofilm at $16 \mathrm{~h}$.

ethanol and $0.25 \%$ (wt/vol) $\mathrm{NaOH}$ at $60^{\circ} \mathrm{C}$ for $1 \mathrm{~h}$ (31). Stock solutions of hydrolyzed simvastatin were stored at $-20^{\circ} \mathrm{C}$ at $20 \mathrm{mg} / \mathrm{mL}(48 \mathrm{mM})$. Ergosterol (Fluka, Switzerland) was dissolved at $50 \mathrm{mg} / \mathrm{mL}(126 \mathrm{mM})$ in Tween 80:ethanol $(1: 1)$ at $60^{\circ} \mathrm{C}$ for $10 \mathrm{~min}$. Filipin (Polysciences Inc.) was reconstituted in DMSO at $50 \mathrm{mg} / \mathrm{mL}$, as described (32-34). Safranin (Acros Organics) was solubilized in $\mathrm{H}_{2} \mathrm{O}$ at a working concentration of $0.1 \%$ (wt/vol) $(25,26)$.

Growth of C. albicans strains. Candida albicans laboratory strain BWP17wt and the isogenic mutants deleted for both alleles of NDH51 (ndh51) and PDX1 (pdx1-29) have been previously described $(23,24)$, as have clinical isolates from blood, skin, and mucosal surfaces (35). All strains were maintained at $-80^{\circ} \mathrm{C}$ in $20 \%$ glycerol. Working cultures were plated on YPD (yeast/peptone/dextrose) agar plates (1\% yeast extract, 2\% Bacto-peptone, $100 \mathrm{mM}$ dextrose, $1.5 \%$ Bacto-agar) at $30^{\circ} \mathrm{C}$ for $48 \mathrm{~h}$. A single colony of the desired strain was inoculated into $2.5 \mathrm{~mL}$ YPD medium and incubated overnight at $30^{\circ} \mathrm{C}$ with shaking.

Biofilm assays. The biofilm assay has been previously published (25-27). Overnight cultures were diluted to a concentration of $2.5 \times 10^{5}$ colonyforming units/mL in YPD $\left(\mathrm{OD}_{600}\right)$. Yeast cells $(100 \mu \mathrm{L})$ were inoculated into each well of a 96-well flat-bottom polystyrene culture plate (Corning 3595) and incubated at $37^{\circ} \mathrm{C}$ for 3,6 , or $16 \mathrm{~h}$ in a humidified chamber. Simvastatin was added at concentrations ranging from 1 to $25 \mu \mathrm{M}$, ergosterol at $90 \mu \mathrm{M}$ and filipin at $50 \mu \mathrm{g} / \mathrm{mL}$, as indicated. Cells not treated with simvastatin were incubated with solvent $(0.25 \% \mathrm{NaOH} / 15 \%$ ethanol) equivalently diluted in YPD. Each reaction was performed in triplicate wells. For quantitation, medium was removed at the indicated time point, and biofilms were washed twice with PBS, stained with $100 \mu \mathrm{L}$ safranin for $10 \mathrm{~min}$ at room temperature, washed $3 \times$ with distilled $\mathrm{H}_{2} \mathrm{O}$, and scanned at $\mathrm{OD}_{405}$ with a Spectra Max 190 plate reader (Molecular Devices, Sunnyvale, CA) using Soft max Pro 4.3.1 software. In certain experiments, filipin $(50 \mu \mathrm{g} / \mathrm{mL})$ was added to planktonic cells after 16-h incubation with simvastatin $(5 \mu \mathrm{M}) \pm \operatorname{ergosterol}(90 \mu \mathrm{M})$; cells were observed immediately using a DAPI filter at $358 \mathrm{~nm}$ excitation and $461 \mathrm{~nm}$ emission wavelength. For all biofilms, microscopic analysis of staining with safranin or filipin was performed with an Olympus IX70 fluorescent microscope using a $40 \times$ objective lens. Digital images were captured with an Optronics Engineering Camera (DEI-750) and Image-Pro Plus 5.0 software.

Statistical analysis. In the dose-response experiments, nine separate experiments were done across the entire range of simvastatin concentrations $(0-25 \mu \mathrm{M})$. In a post hoc analysis, the Wilcoxon signed ranks test was used for paired comparison (total comparisons $=6$ ), and the critical $p$ value was adjusted with the Bonferroni correction $(0.05 / 6=0.008)$.

For the experiments examining the effects of exogenous ergosterol in reconstituting biofilm formation, the Wilcoxon signed ranks test was used to test whether the addition of ergosterol resulted in the difference of the observed production of biofilm as measured by spectrophotometry. Again, the Bonferroni correction was applied to adjust for the three pair-wise comparisons $(1,2.5$, and $5 \mu \mathrm{M}$ simvastatin), which resulted in the critical $p$ value of 0.017 .

\section{RESULTS}

Assessment of biofilm production. Spectrophotometric analysis of safranin staining was used to quantitate the effects of simvastatin $(1-25 \mu \mathrm{M})$ on mature biofilms produced by $C$.

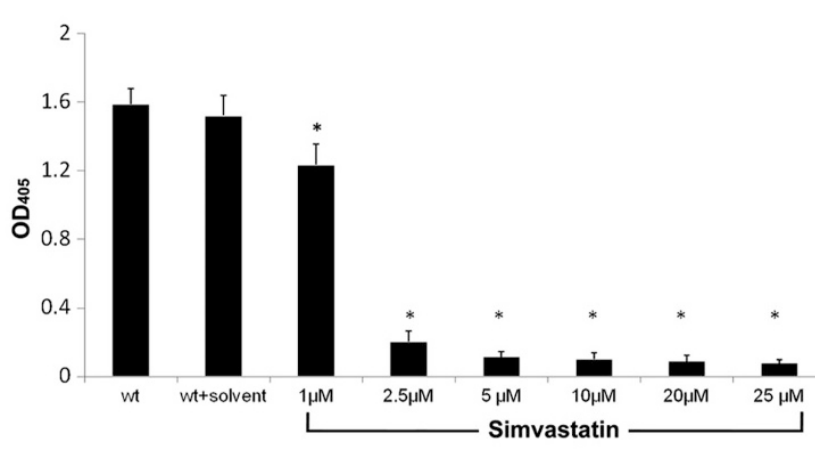

Figure 2. Assessment of mature biofilms at $16 \mathrm{~h}$ in the absence or presence of the indicated concentrations of simvastatin. Spectrophotometric quantitation of safranin staining was performed at $\mathrm{OD}_{405}$. Bars represent mean $\pm \mathrm{SD}$ for $n=9$ experiments with the indicated concentration of simvastatin. ${ }^{*} p=$ 0.0007 for 1.0 to $25 \mu \mathrm{M}$ simvastatin compared with the wild-type strain + solvent.

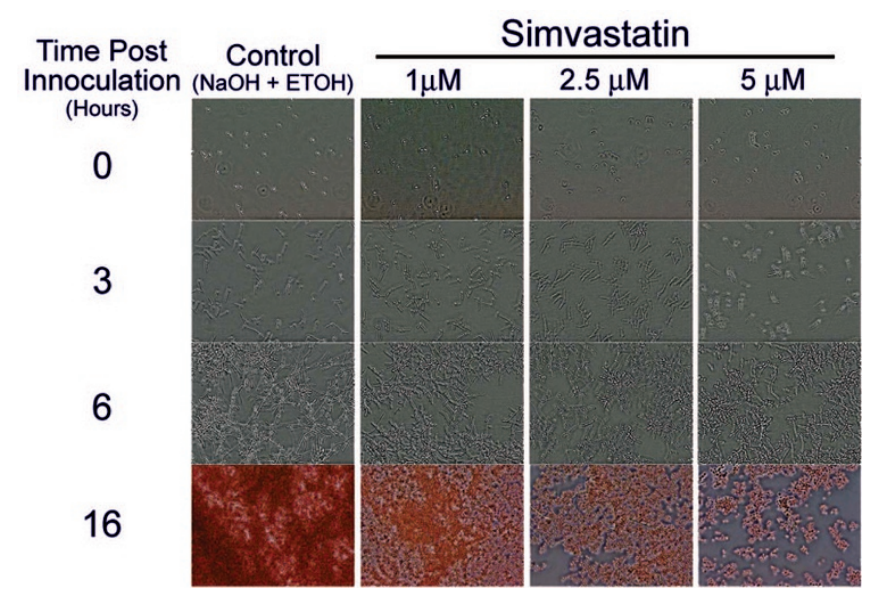

Figure 3. Time- and dose-dependent microscopy of biofilm formation in the absence or presence of the indicated concentrations of simvastatin.

albicans (Fig. 2). After 16-h incubation, a concentration of 1 $\mu \mathrm{M}$ simvastatin reduced biofilm formation by $19 \%$. However, concentrations of 2.5 to $25 \mu \mathrm{M}$ simvastatin reduced biofilm formation by $\geq 87 \%$. These reductions were statistically significant $(p=0.007)$. Quantitative cultures of organisms in biofilms showed that simvastatin concentrations $\leq 5 \mu \mathrm{M}$ were not candidacidal; simvastatin concentrations $\geq 10 \mu \mathrm{M}$ led to a 1-log kill.

To determine whether early changes in adhesion or hyphal formation were responsible for simvastatin's effects on mature biofilm, biofilms were assessed microscopically after 0,3 , or $6 \mathrm{~h}$ treatment with solvent (control) or the indicated concentration of simvastatin (Fig. 3). Concentrations between 1 and $5 \mu \mathrm{M}$ were chosen for detailed analysis because of the results in Figure 2 and because these concentrations are $\sim 20$ - to 100 -fold less than those previously reported to be cidal for $C$. albicans (36). At time 0 and after $3 \mathrm{~h}$, similar numbers of cells adhered in the presence of $0,1,2.5$, or $5 \mu \mathrm{M}$ simvastatin, whereas at $6 \mathrm{~h}$, both untreated and simvastatin-treated cells produced hyphae. However, as assessed by safranin staining at $16 \mathrm{~h}$, C. albicans cells treated with 2.5 or $5 \mu \mathrm{M}$ simvastatin showed marked impairment of biofilm production, compared with cells treated with solvent alone. 


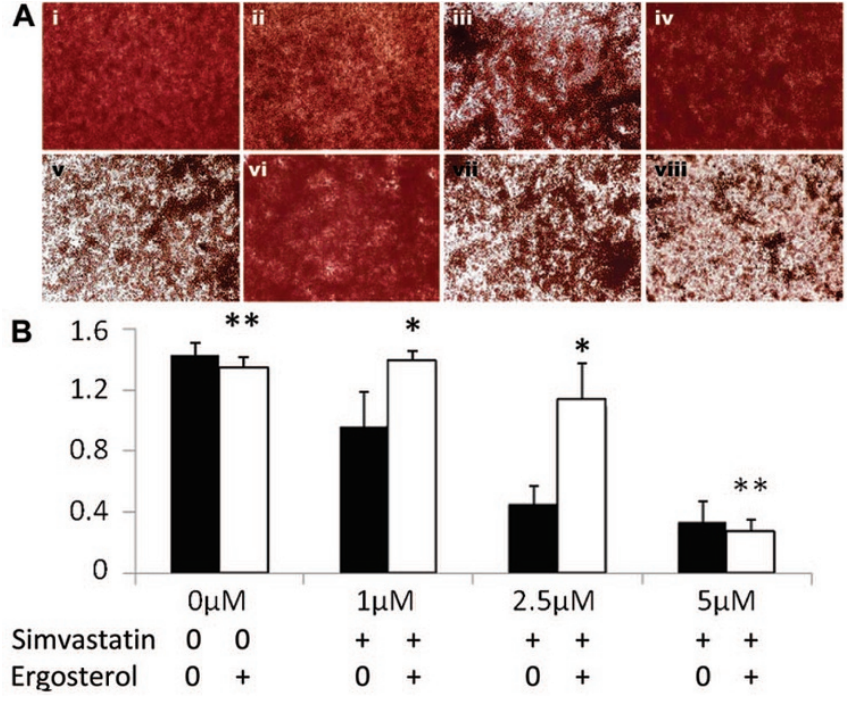

Figure 4. A. Microscopic analysis of reconstitution of simvastatin-inhibited biofilm formation by ergosterol. Panels $i, i i i, v$, and vii are biofilms treated with $\mathrm{NaOH} /$ ethanol solvent (i) or $1 \mu \mathrm{M}$ (iii), $2.5 \mu \mathrm{M}(v)$, or $5 \mu \mathrm{M}$ (vii) simvastatin, respectively. Panels $i i, i v, v i$, and viii received $90 \mu \mathrm{M}$ ergosterol in addition to solvent and simvastatin. B. Spectrophotometric analysis of reconstitution of simvastatin-inhibited biofilm formation by ergosterol. mean $\pm \mathrm{SD}$ for $n=7$ experiments with the indicated concentration of simvastatin. $\square$ : mean \pm SD for $n=7$ experiments with the indicated concentration of simvastatin plus $90 \mu \mathrm{M}$ ergosterol. ${ }^{*} p=0.018$ for the indicated pairs, **not significant.

Mechanism of inhibition. Because concentrations of simvastatin that inhibited biofilm production $(\geq 1 \mu \mathrm{M})$ did not seem to affect growth, adherence, or hyphal formation of $C$. albicans (Fig. 2), we used microscopy to assess the ability of exogenous ergosterol to overcome the inhibitory effects of simvastatin (Fig. 4A). Ergosterol did not augment safranin staining of $16 \mathrm{~h}$ biofilms formed by control organisms treated with solvent $(\mathrm{NaOH} /$ ethanol). In the presence of 1 or $2.5 \mu \mathrm{M}$ simvastatin, production of $C$. albicans biofilm was visually impaired; however, addition of ergosterol restored safranin staining. In the presence of $5 \mu \mathrm{M}$ simvastatin, the addition of ergosterol was not sufficient to restore safranin staining, suggesting that other statin-dependent or -independent processes may be compromised under these conditions.

These results were substantiated in a spectrophotometric assay (Fig. 4B). In the absence of simvastatin, addition of ergosterol did not increase safranin staining of mature $(16 \mathrm{~h})$ biofilms. Incubation with $1 \mu \mathrm{M}$ simvastatin led to a decrease in staining, which improved with the addition of ergosterol $(p=0.018)$. The same result was true for $2.5 \mu \mathrm{M}$ simvastatin: the addition of ergosterol restored safranin staining $(p=0.018)$. However, in the presence of $5 \mu \mathrm{M}$ simvastatin, ergosterol proved ineffective, again indicating that simvastatin's inhibitory effects may not be confined to ergosterol biosynthesis.

The effects of simvastatin on ergosterol production were corroborated by staining with filipin, a dye that is specifically taken up by ergosterol $(33,34)$. Detection of ergosterol in the cell wall and hyphae of $C$. albicans cells was quite distinct in the absence of simvastatin, but in the presence of simvastatin, ergosterol was spotty and disordered (Fig. 5). The addition of ergosterol to the simvastatin incubation mixture restored fili-
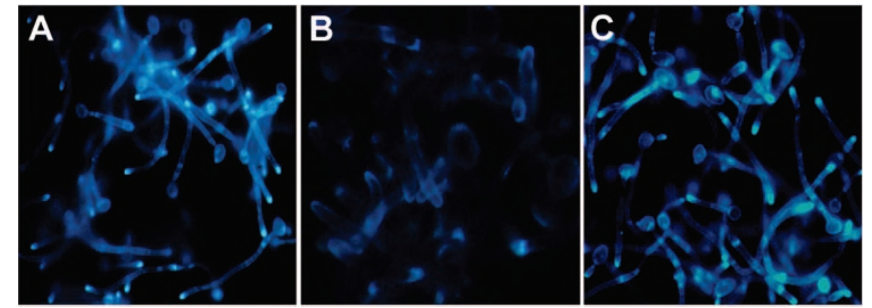

Figure 5. Filipin staining of planktonic Candida albicans cells in the absence $(A)$, and presence of $5 \mu \mathrm{M}$ simvastatin $(B)$, or $5 \mu \mathrm{M}$ simvastatin +90 $\mu \mathrm{M}$ ergosterol $(C)$.

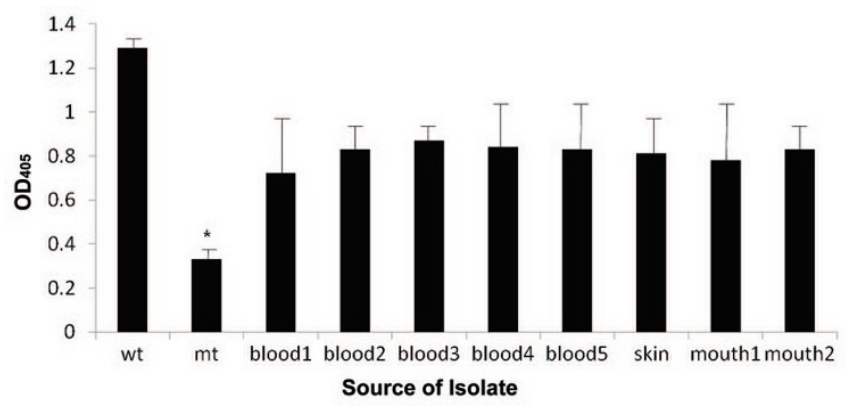

Figure 6. Biofilm production by the wild-type strain BWP17wt, the mutant $p d x 1-29$, and eight clinical isolates. Results are the mean \pm SD for $n=3$ experiments. $* p=0.01$.

pin staining in planktonic cells, even though biofilms treated with $5 \mu \mathrm{M}$ simvastatin were not rescued by ergosterol (Fig. $4 \mathrm{~A}$ and $B$ ). These results provide additional confirmation that at least one mechanism by which simvastatin inhibits $C$. albicans relates to interference with ergosterol synthesis, which may be more susceptible to simvastatin in organisms composing a biofilm, as opposed to planktonic cells.

Corroboration with clinical isolates. Biofilm production by clinical isolates from blood $(n=5)$, skin $(n=2)$, and mucosal surfaces $(n=2)$ was assessed by safranin staining in the absence or presence of $5 \mu \mathrm{M}$ simvastatin (Fig. 6). Laboratory strain BWP17wt proved to be the most vigorous biofilm producer in vitro, whereas the biofilm produced by mutant $p d x 1-29$ was markedly decreased as previously observed. All clinical isolates produced biofilms, but safranin staining was less intense than with the laboratory strain. By spectrophotometric assay, biofilm formation by four blood isolates from patients with catheter-associated candidemia was inhibited by $5 \mu \mathrm{M}$ simvastatin, with decreases in $\mathrm{OD}_{405}$ ranging from 53 to $59 \%$. The effects of simvastatin on biofilms formed by skin and mucosal isolates were not tested.

\section{DISCUSSION}

Results of these in vitro studies show that noncandidacidal concentrations of simvastatin $(1,2.5$, or $5 \mu \mathrm{M})$ inhibit biofilm production in vitro by laboratory and clinical isolates of $C$. albicans in both microscopic and spectrophotometric assays. Although microscopic and spectrophotometric assays showed a modest inhibitory effect of $1 \mu \mathrm{M}$ simvastatin, repeated analysis in a spectrophotometric assay showed statistically significant inhibition $\geq 87 \%$ at concentrations of $2.5 \mu \mathrm{M}$ and above. At concentrations $\leq 5 \mu \mathrm{M}$, simvastatin does not inhibit 
growth of $C$. albicans, and neither adhesion at $3 \mathrm{~h}$ nor hyphal production at $6 \mathrm{~h}$ is impaired in organisms incubated with 1 , 2.5, or $5 \mu \mathrm{M}$ simvastatin (Fig. 3).

The ability of exogenous ergosterol to restore biofilm formation after treatment with 1 or $2.5 \mu \mathrm{M}$ simvastatin (Fig. $4 A$ and $B$ ) indicates that at least one inhibitory mechanism is interference with ergosterol synthesis. Although genes involved in the ergosterol pathway are known to contribute to biofilm formation $(37,38)$, the failure of ergosterol to restore biofilms treated with $5 \mu \mathrm{M}$ simvastatin suggests that concentrations $\geq 5 \mu \mathrm{M}$ may impair other metabolic processes as well, such as statin-dependent geranylgeranylation, farnesylation, or production of exopolysaccharide. Interestingly, as the simvastatin concentration exceeded $5 \mu \mathrm{M}$, quantitative cultures of biofilms yielded increasing numbers of petite mutants, which represent organisms that have lost mitochondrial DNA. Petite mutants have been reported in Candida glabrata with simvastatin concentrations of $60 \mu \mathrm{M}$ (39).

Although enzyme conformation and location of the active site lysine differ between Class II (bacterial) and Class I (eukaryotic) HMG CoA reductases, the isoprenoid pathway is essential for many microbes (40-42). Although Class II enzymes are much less sensitive to inhibition by statins, inhibition of bacterial or fungal growth by interference with the isoprenoid pathway is well described. An inhibitor of squalene synthetase, an intermediate step in the cholesterol pathway, blocked staphyloxanthin production and attendant virulence in Staphylococcus aureus (43). Lovastatin-mediated growth inhibition has been reported for several pathogenic and nonpathogenic yeasts and one mold $(31,39,44)$. For example, 100 $\mu \mathrm{M}$ simvastatin or atorvastatin inhibited growth of four Candida species (C. albicans, tropicalis, glabrata, and parapsilosis) as well as Aspergillus fumigatus (36).

Our studies are the first to examine the effect of statins on C. albicans biofilm. The lowest concentration of simvastatin that impaired biofilm formation in our studies $(1 \mu \mathrm{M})$ is 10 -fold less than the concentration that inhibited growth of $C$. albicans in our experiments and $\sim 60$ to 100 -fold less than the candidacidal concentration reported in previous work (36). Nevertheless, $1 \mu \mathrm{M}$ simvastatin is still $\sim 30$-fold higher than the plasma level achieved after standard oral dosing in humans (28). Although pharmacoepidemiologic studies have found no increased risk for fetal anomalies in pregnant women taking statins (45), reformulating simvastatin as a coating for catheter lumens may be a more feasible approach, as has been done with other substances such as EDTA or amphotericin, where oral dosage is impractical $(46,47)$.

Although these studies report an inhibitory effect of statins on biofilm production by $C$. albicans laboratory and clinical isolates in vitro, in vivo studies in an animal model of catheterassociated bloodstream infection will be required to confirm clinical relevance. It is certainly possible that other statins or pharmacologic analogs will prove even more effective than simvastatin, either in vitro or in vivo. Indeed, a small molecule screen to identify potentially effective compounds is underway with our collaborators. The studies reported here represent a first step in demonstrating that interference with an essential pathway of lipid synthesis in C. albicans may have unex- pected and potentially clinically relevant effects on biofilm formation.

Acknowledgments. We thank Vladana Milisavljevic, M.D., Assistant Professor of Neonatology, UCLA, for technical advice regarding the biofilm assays, and Veronika Northrup, M.P.H., Biostatistical Support Unit, Yale Center for Clinical Investigation, for guidance regarding statistical methods. Mr. Geoffrey Liu won a Student Research Award from the Pediatric Academic Societies, Honolulu, May, 2008.

\section{REFERENCES}

1. Pfaller MA, Jones RN, Doern GV, Sader HS, Messer SA, Houston A, Coffman S, Hollis RJ 2000 Bloodstream infections due to Candida species: SENTRY antimicrobial surveillance program in North America and Latin America 1997-1998. Antimicrob Agents Chemother 44:747-751

2. Beck-Sague C, Jarvis WR 1993 Secular trends in the epidemiology of nosocomial fungal infections in the United States, 1980-1990. National Nosocomial Infections Surveillance System. J Infect Dis 167:1247-1251

3. Rennert G, Rennert HS, Pitlik S, Finkelstein R, Kitzes-Cohen R 2000 Epidemiology of candidemia - a nationwide survey in Israel. Infection 28:26-29

4. Saiman L, Ludington E, Pfaller M, Rangel-Frausto S, Wiblin RT, Dawson J, Blumberg H, Patterson J, Rinaldi M, Edwards JE, Wenzel RP, Jarvis W 2000 Risk factors for candidemia in neonatal intensive care unit patients. Pediatr Infect Dis J $19: 319-324$

5. Zaoutis TE, Argon J, Chu J, Berlin JA, Walsh TJ, Feudtner C 2005 The epidemiology and attributable outcomes of candidemia in adults and children hospitalized in the United States: a propensity analysis. Clin Infect Dis 41:1232-1239

6. Faix RG 1992 Invasive neonatal candidiasis: comparison of albicans and parapsilosis infection. Pediatr Infect Dis J 11:88-93

7. Chapman RL, Faix RG 2000 Persistently positive cultures and outcome in invasive neonatal candidiasis. Pediatr Infect Dis J 19:822-827

8. Costa SF, Marinho I, Araujo EA, Manrique AE, Medeiros EA, Levin AS 2000 Nosocomial fungaemia: a 2-year prospective study. J Hosp Infect 45:69-72

9. Gudlaugsson O, Gillespie S, Lee K, Vande Berg J, Hu J, Messer S, Herwaldt L, Pfaller M, Diekema D 2003 Attributable mortality of nosocomial candidemia, revisited. Clin Infect Dis 37:1172-1177

10. Zaoutis TE, Greves HM, Lautenbach E, Bilker WB, Coffin SE 2004 Risk factors for disseminated candidiasis in children with candidemia. Pediatr Infect Dis J 23:635641

11. Baillie GS, Douglas LJ 1998 Effect of growth rate on resistance of Candida albicans biofilms to antifungal agents. Antimicrob Agents Chemother 42:1900-1905

12. Chandra J, Kuhn DM, Mukherjee PK, Hoyer LL, McCormick T, Ghannoum MA 2001 Biofilm formation by the fungal pathogen Candida albicans: development, architecture, and drug resistance. J Bacteriol 183:5385-5394

13. Nobile CJ, Mitchell AP 2006 Genetics and genomics of Candida albicans biofilm formation. Cell Microbiol 8:1382-1391

14. Almirante B, Rodriguez D, Park BJ, Cuenca-Estrella M, Planes AM, Almela M, Mensa J, Sanchez F, Ayats J, Gimenez M, Saballs P, Fridkin SK, Morgan J, Rodriguez-Tudela JL, Warnock DW, Pahissa A; Barcelona Candidemia Project Study Group 2005 Epidemiology and predictors of mortality in cases of Candida bloodstream infection: results from population-based surveillance, Barcelona, Spain, from 2002 to 2003. J Clin Microbiol 43:1829-1835

15. Benjamin DK Jr, Ross K, McKinney RE Jr, Benjamin DK, Auten R, Fisher RG 2000 When to suspect fungal infection in neonates: a clinical comparison of Candida albicans and Candida parapsilosis fungemia with coagulase-negative staphylococcal bacteremia. Pediatrics 106:712-718

16. Karlowicz MG, Hashimoto LN, Kelly RE Jr, Buescher ES 2000 Should central venous catheters be removed as soon as candidemia is detected in neonates? Pediatrics 106:E63

17. Nucci M, Colombo AL, Silveira F, Richtmann R, Salomao R, Branchini ML, Spector N 1998 Risk factors for death in patients with candidemia. Infect Control Hosp Epidemiol 19:846-850

18. Mermel LA, Allon M, Bouza E, Craven DE, Flynn P, O'Grady NP, Raad II, Rijnders BJ, Sheretz RJ, Warren DK 2009 Clinical practice guidelines for the diagnosis and management of intravascular catheter-related infection: 2009 update by the Infectious Diseases Society of America. Clin Infect Dis 49:1-45

19. Rex JH, Walsh TJ, Sobel JD, Filler SG, Pappas PG, Dismukes WE, Edwards JE 2000 Practice guidelines for the treatment of candidiasis. Infectious Diseases Society of America. Clin Infect Dis 30:662-678

20. Manzoni P, Stolfi I, Pugni L, Decembrino L, Magnani C, Vetrano G, Tridapalli E, Corona G, Giovannozzi C, Farina D, Arisio R, Merletti F, Maule M, Mosca F, Pedicino R, Stronati M, Mostert M, Gomirato G 2007 A multicenter, randomized trial of prophylactic fluconazole in preterm neonates. N Engl J Med 356:2483-2495

21. Shorr AF, Chung K, Jackson WL, Waterman PE, Kollef MH 2005 Fluconazole prophylaxis in critically ill surgical patients: a meta-analysis. Crit Care Med 33:1928-1935; quiz 1936

22. Healy CM, Campbell JR, Zaccaria E, Baker CJ 2008 Fluconazole prophylaxis in extremely low birth weight neonates reduces invasive candidiasis mortality rates 
without emergence of fluconazole-resistant Candida species. Pediatrics 121:703710

23. McDonough JA, Bhattacherjee V, Sadlon T, Hostetter MK 2002 Involvement of Candida albicans NADH dehydrogenase complex I in filamentation. Fungal Genet Biol 36:117-127

24. Vellucci VF, Gygax SE, Hostetter MK 2007 Involvement of Candida albicans pyruvate dehydrogenase complex protein X (PdX1) in filamentation. Fungal Genet Biol 44:979-990

25. Branchini ML, Pfaller MA, Rhine-Chalberg J, Frempong T, Isenberg HD 1994 Genotypic variation and slime production among blood and catheter isolates of Candida parapsilosis. J Clin Microbiol 32:452-456

26. Christensen GD, Simpson WA, Bisno AL, Beachey EH 1982 Adherence of slimeproducing strains of Staphylococcus epidermidis to smooth surfaces. Infect Immun $37: 318-326$

27. Milisavljevic V, Tran LP, Batmalle C, Bootsma HJ 2008 Benzyl alcohol and ethanol can enhance the pathogenic potential of clinical Staphylococcus epidermidis strains. Am J Infect Control 36:552-558

28. Corsini A, Bellosta S, Baetta R, Fumagalli R, Paoletti R, Bernini F 1999 New insights into the pharmacodynamic and pharmacokinetic properties of statins. Pharmacol Ther 84:413-428

29. Mahley Robert W, Bersot Thomas P 2005 Drug therapy for hypercholesterolemia and dyslipidemia. In: Brunton LL, Lazo JS, Parker KL (eds) Goodman \& Gilman's the Pharmacological Basis of Therapeutics, McGraw-Hill, New York, pp 933-966

30. Lupetti A, Danesi R, Campa M, Del Tacca M, Kelly S 2002 Molecular basis of resistance to azole antifungals. Trends Mol Med 8:76-81

31. Lorenz RT, Parks LW 1990 Effects of lovastatin (mevinolin) on sterol levels and on activity of azoles in Saccharomyces cerevisiae. Antimicrob Agents Chemother 34:1660-1665

32. Van Leeuwen MR, Smant W, de Boer W, Dijksterhuis J 2008 Filipin is a reliable in situ marker of ergosterol in the plasma membrane of germinating conidia (spores) of Penicillium discolor and stains intensively at the site of germ tube formation. J Microbiol Methods 74:64-73

33. Wachtler V, Rajagopalan S, Balasubramanian MK 2003 Sterol-rich plasma membrane domains in the fission yeast Schizosaccharomyces pombe. J Cell Sci 116:867874

34. Martin SW, Konopka JB 2004 Lipid raft polarization contributes to hyphal growth in Candida albicans. Eukaryot Cell 3:675-684

35. Hostetter MK, Lorenz JS, Preus L, Kendrick KE 1990 The iC3b receptor on Candida albicans: subcellular localization and modulation of receptor expression by glucose. J Infect Dis 161:761-768
36. Macreadie IG, Johnson G, Schlosser T, Macreadie PI 2006 Growth inhibition of Candida species and Aspergillus fumigatus by statins. FEMS Microbiol Lett 262:9-13

37. Borecka-Melkusova S, Moran GP, Sullivan DJ, Kucharikova S, Chorvat D Jr, Bujdakova H 2009 The expression of genes involved in the ergosterol biosynthesis pathway in Candida albicans and Candida dubliniensis biofilms exposed to fluconazole. Mycoses 52:118-128

38. Khot PD, Suci PA, Miller RL, Nelson RD, Tyler BJ 2006 A small subpopulation of blastospores in Candida albicans biofilms exhibit resistance to amphotericin B associated with differential regulation of ergosterol and beta-1,6-glucan pathway genes. Antimicrob Agents Chemother 50:3708-3716

39. Westermeyer C, Macreadie IG 2007 Simvastatin reduces ergosterol levels, inhibits growth and causes loss of mtDNA in Candida glabrata. FEMS Yeast Res 7:436441

40. Hedl M, Tabernero L, Stauffacher CV, Rodwell VW 2004 Class II 3-hydroxy-3methylglutaryl coenzyme A reductases. J Bacteriol 186:1927-1932

41. Wilding EI, Brown JR, Bryant AP, Chalker AF, Holmes DJ, Ingraham KA, Iordanescu S, So CY, Rosenberg M, Gwynn MN 2000 Identification, evolution, and essentiality of the mevalonate pathway for isopentenyl diphosphate biosynthesis in gram-positive cocci. J Bacteriol 182:4319-4327

42. Hu W, Sillaots S, Lemieux S, Davison J, Kauffman S, Breton A, Linteau A, Xin C, Bowman J, Becker J, Jiang B, Roemer T 2007 Essential gene identification and drug target prioritization in Aspergillus fumigatus. PLoS Pathog 3:e24

43. Liu CI, Liu GY, Song Y, Yin F, Hensler ME, Jeng WY, Nizet V, Wang AH, Oldfield E 2008 A cholesterol biosynthesis inhibitor blocks Staphylococcus aureus virulence. Science 319:1391-1394

44. Gyetvai A, Emri T, Takacs K, Dergez T, Fekete A, Pesti M, Pocsi I, Lenkey B 2006 Lovastatin possesses a fungistatic effect against Candida albicans, but does not trigger apoptosis in this opportunistic human pathogen. FEMS Yeast Res 6:11401148

45. Ofori B, Rey E, Berard A 2007 Risk of congenital anomalies in pregnant users of statin drugs. Br J Clin Pharmacol 64:496-509

46. Zumbuehl A, Ferreira L, Kuhn D, Astashkina A, Long L, Yeo Y, Iaconis T, Ghannoum M, Fink GR, Langer R, Kohane DS 2007 Antifungal hydrogels. Proc Natl Acad Sci USA 104:12994-12998

47. Raad I, Chatzinikolaou I, Chaiban G, Hanna H, Hachem R, Dvorak T, Cook G, Costerton W 2003 In vitro and ex vivo activities of minocycline and EDTA against microorganisms embedded in biofilm on catheter surfaces. Antimicrob Agents Chemother 47:3580-3585 